\title{
The Structure and Properties of Copolyaspartate I. Copoly(butyl-L-aspartate-benzyl-L-aspartate)
}

\author{
Yoshiharu Tsujita, Mikio Fukagawa, ${ }^{*}$ and Ichitaro Uematsu* \\ Department of Polymer Engineering, Nagoya Institute of Technology, \\ Gokiso, Showa-ku, Nagoya 466, Japan \\ *Department of Polymer Chemistry, Tokyo Institute of Technology, \\ Meguro-ku, Tokyo 152, Japan
}

(Received January 30, 1982)

\begin{abstract}
The $\alpha$ helices of copoly(butyl-L-aspartate-benzyl-L-aspartate) prepared by substituting some of the benzyl groups in the side chains of poly( $\beta$-benzyl-L-aspartate) by butyl groups, were transformed, throughout the entire range of butylation tested, into $\omega$ helices with a tetragonal packing when heated up to $140^{\circ} \mathrm{C}$. The $\alpha-\omega$ transition temperature was about $100^{\circ} \mathrm{C}$ for copolyaspartates of butylation less than $30 \%$ and near $130^{\circ} \mathrm{C}$ for copolyaspartates of butylation more than $30 \%$. In the case of more than $30 \%$ butylation the $\alpha-\omega$ transition was furthermore accompanied by a change from the right handed $\alpha$ helix to the left handed $\omega$ helix. The $\alpha-\omega$ transition resulted in a remarkable change in the magnitude of the dynamic modulus and an exothermic peak. It was concluded that the $\omega$ helix of copoly(butyl-L-aspartate-benzyl-L-aspartate) was based on the formation of stacks between benzyl and butyl groups as well as the $\omega$ helix consisting of stacks between the benzyl groups of poly( $\beta$-benzyl-L-aspartate).

KEY WORDS $\alpha-\omega$ Transition / $\omega$-Helix / Helix Sense / Stacks /

Copoly(butyl-L-aspartate-benzyl-L-aspartate) /
\end{abstract}

It is well known that a left handed helix is stable in solution and in a solid state of $\operatorname{poly}(\beta$-benzyl-Laspartate)(PBLAsp), in contrast to a right handed $\alpha$ helix of poly-L-peptides. ${ }^{1}$ The $\alpha$ helix of PBLAsp transforms into $\omega$ helix only in a solid state by heat treatment (near $140^{\circ} \mathrm{C}$ ). Bradbury et al. ${ }^{2}$ have shown that the molecule in the $\omega$ helix forms a structure of the type described earlier by Bragg, Kendrew, and Perutz. ${ }^{3}$ This structure of the $\omega$ helix has four residues per turn of a helix and the $\omega$ helices are tetragonally packed. Thus, the $\alpha-\omega$ transition was accompanied by a change from the right handed $\alpha$ helix to the left handed $\omega$ helix and the transformation from hexagonal to tetragonal packing. The exothermic peak ${ }^{4-6}$ and the volume contraction $^{7}$ have been observed for the $\alpha-\omega$ transition.

Malcolm ${ }^{8,9}$ has reported that a right handed $\alpha$ helix of PBLAsp prepared by monolayer technique also transforms into a left handed $\omega$ helix by heating to $c a \cdot 160^{\circ} \mathrm{C}$; that is, both a reversal of the helix sense and the transformation from hexagonal to tetragonal packing occurred in the $\alpha-\omega$ transition. Furthermore, for poly ( $\beta$-chlorobenzyl-L-aspartate), such a reversal in the solid state was confirmed by Tsuboi et al. ${ }^{10}$ Reversal of the helix sense occurs easily for a certain polyaspartate on the $\alpha-\omega$ transition.

$\operatorname{Poly}(\beta$-butyl-L-aspartate) is known to be a right handed $\alpha$ helix, contrary to the helix sense of PBLAsp. However, it was found that this compound does not transform into the $\omega$ helix. ${ }^{11,12}$ Thus it may be expected that copoly(butyl-Laspartate-benzyl-L-aspartate) (copoly(BuLAspBeLAsp) retains either a left handed or right handed $\alpha$ helix, depending on the degree of butylation and that copoly(BuLAsp-BeLAsp) at a low degree of butylation transforms into the $\omega$ helix on heat treatment.

In the present paper, the formation of the $\omega$ helix is studied for copoly(BuLAsp-BeLAsp). The $\alpha-\omega$ transition of copoly(BuLAsp-BeLAsp) was investigated on the basis of the change from hexagonal to tetragonal packing and reversal of helix sense. 
Furthermore, the viscoelastic and thermal behavior in the $\alpha-\omega$ transition region along with the $\omega-\beta$ transformation were studied.

\section{EXPERIMENTAL}

\section{Materials}

$N$-Carboxy- $\beta$-benzyl-L-aspartate anhydride (NCA) was synthesized by Leuch's method with $\beta$ benzyl-L-aspartate produced from aspartic acid. ${ }^{13}$ The purified NCA was polymerized in about a $5 \%$ (w/v) ethylene dichloride solution, using triethylamine as the initiator. The PBLAsp thus obtained had an intrinsic viscosity of $[\eta]=0.426$ in dichloroacetic acid, which gave a viscosity average molecular weight of $6.6 \times 10^{4}$ as calculated from the viscosity molecular weight relation of Doty et al. ${ }^{14}$ for poly( $\gamma$-benzyl-L-glutamate). Copoly(BuLAspBeLAsp) was prepared by butylation of PBLAsp following the method reported by Bradbury et al. ${ }^{15}$ Six samples with various degrees of butylation as shown in Table I were produced with different conditions of reaction, i.e., content of concentrated sulfuric acid and $n$-butyl alcohol and reaction time. The degree of butylation was evaluated from the NMR spectra of the benzyl and butyl groups.

Solid films $0.1 \mathrm{~mm}$ in thickness were prepared by casting from $c a .5 \%(\mathrm{w} / \mathrm{v})$ chloroform solution at room temperature. For infrared absorption spectra measurements, thin films with $0.01-0.03 \mathrm{~mm}$ thick were prepared by the same method.

\section{Measurements}

NMR spectra were recorded on a $100 \mathrm{MHz}$ spectrometer (Japan Electron Optics Laboratory Co. Ltd.) at room temperature in the $\tau$ region from
0 to $10 \mathrm{ppm}$. The polypeptide solution of trifluoroacetic acid had concentration of $10 \%(\mathrm{w} / \mathrm{v})$ and tetramethyl silane was used as an internal standard.

Dynamic viscoelastic measurements wére carried out on a Rheovibron DDV-II (Toyo Baldwin Co. Ltd.) at a frequency of $110 \mathrm{~Hz}$ over a temperature range from -100 to $230^{\circ} \mathrm{C}$ at the heating rate of $1^{\circ} \mathrm{C} / 3 \mathrm{~min}$.

Infrared absorption spectra were recorded in the wave number range from 400 to $4000 \mathrm{~cm}^{-1}$ with an infrared grating spectrophotometer (Japan Spectroscopic Co. Ltd.). The wave numbers of all spectra were calibrated using a polystyrene film as a standard specimen.

$\mathrm{X}$-Ray photographs were taken on flat films with $\mathrm{Cu}-K \alpha(1.54 \AA)$ radiation with a Rigaku Denki Xray diffractometer. The distance from specimen to camera film $(6.896 \mathrm{~cm})$ was calibrated by silicon powders.

The DTA measurements were carried out on a differential thermal analyser with $10 \mathrm{mg}$ of sample at a heating rate of $4^{\circ} \mathrm{C} / \mathrm{min}$. The temperature was calibrated on the basis of the melting points of benzoic acid, indium, and tin.

\section{RESULTS AND DISCUSSION}

\section{Infrared Absorption Spectroscopy}

The relationships between the helix conformation and characteristic band positions for PBLAsp are summarized in Table II. Tables III, IV, and V give characteristic band positions observed for the ascast films, and the films annealed at $140^{\circ} \mathrm{C}$ and at $210^{\circ} \mathrm{C}$, respectively. The copoly(BuLAsp-BeLAsp) obtained here was designated as $\mathrm{Bu}-1-\mathrm{Bu}-6$, de-

Table I. Conditions of butylation

\begin{tabular}{|c|c|c|c|c|c|c|}
\hline \multirow{2}{*}{ Sample } & $\begin{array}{l}\text { Content of } \\
\text { PBLAsp }\end{array}$ & $\begin{array}{l}\text { Content of } \\
\mathrm{CHCl}_{3}\end{array}$ & $\begin{array}{c}\text { Content of } \\
\mathrm{H}_{2} \mathrm{SO}_{4}\end{array}$ & $\begin{array}{l}\text { Reaction } \\
\text { time }\end{array}$ & $\begin{array}{l}n \text {-Butyl } \\
\text { alcohol }\end{array}$ & $\begin{array}{l}\text { Degree of } \\
\text { butylation }\end{array}$ \\
\hline & $\mathrm{g}$ & $\mathrm{ml}$ & $\mathrm{ml}$ & $\mathrm{h}$ & $\mathrm{ml}$ & $\%$ \\
\hline $\mathrm{Bu}-1$ & 0.4 & 100 & 0.3 & 72 & 30 & 17.9 \\
\hline $\mathrm{Bu}-2$ & 0.4 & 100 & 0.3 & 72 & 50 & 20.6 \\
\hline $\mathrm{Bu}-3$ & 0.4 & 100 & 0.4 & 100 & 55 & 32.5 \\
\hline $\mathrm{Bu}-4$ & 0.4 & 100 & 0.4 & 145 & 60 & 39.1 \\
\hline $\mathrm{Bu}-5$ & 0.4 & 100 & 1.0 & 190 & 70 & 69.3 \\
\hline $\mathrm{Bu}-6$ & 0.4 & 100 & 1.5 & 214 & 80 & 86.7 \\
\hline
\end{tabular}


The Structure and Properties of Copolyaspartate I.

pending on the degree of butylation as shown in Table I. Comparing band positions (Amide I and II bands) in Table II and III, it was found that the Amide I and II band positions of the as-cast films of

Table II. Band position of PBLAsp $\left(\mathrm{cm}^{-1}\right)^{\mathrm{a}}$

\begin{tabular}{clll}
\hline & $\begin{array}{c}\text { Ester } \\
\mathrm{C}=\mathrm{O}\end{array}$ & Amide I & Amide II \\
& & \\
\hline Left handed $\alpha$ helix & $1735 \pm 2$ & $1666 \pm 2$ & $1557 \pm 2$ \\
Right handed $\alpha$ helix & $1741 \pm 2$ & $1659 \pm 2$ & $1553 \pm 2$ \\
$\omega$ Helix & $1731 \pm 2$ & $1675 \pm 2$ & $1536 \pm 2$ \\
$\beta$ Form & 1726 & 1636 & 1529 \\
\hline
\end{tabular}

a Based on Green et al. ${ }^{4}$ and Bradbury et al. ${ }^{11}$

Table III. Band positions of as-cast films $\left(\mathrm{cm}^{-1}\right)$

\begin{tabular}{lccc}
\hline & Ester C $=\mathrm{O}$ & Amide I & Amide II \\
\hline Bu-1 & 1740 & 1665 & 1555 \\
$\mathrm{Bu}-2$ & 1740 & 1668 & 1556 \\
$\mathrm{Bu}-3$ & 1739 & 1659 & 1550 \\
$\mathrm{Bu}-4$ & 1738 & 1659 & 1550 \\
$\mathrm{Bu}-5$ & 1740 & 1660 & 1550 \\
$\mathrm{Bu}-6$ & 1739 & 1659 & 1549 \\
\hline
\end{tabular}

Table IV. Band positions of films annealed at $140^{\circ} \mathrm{C}\left(\mathrm{cm}^{-1}\right)$

\begin{tabular}{cccc}
\hline & Ester C $=\mathrm{O}$ & Amide I & Amide II \\
\hline PBLAsp $(\omega)$ & 1730 & 1676 & 1533 \\
Bu-1 & 1723 & 1667 & 1532 \\
Bu-2 & 1726 & 1670 & 1532 \\
Bu-3 & 1726 & 1667 & 1533 \\
Bu-4 & 1725 & 1670 & 1533 \\
Bu-5 & 1726 & 1666 & 1533 \\
Bu-6 & 1723 & 1666 & 1531 \\
\hline
\end{tabular}

Table V. Band positions of films annealed at $210^{\circ} \mathrm{C}\left(\mathrm{cm}^{-1}\right)$

\begin{tabular}{cccc}
\hline & Ester C $=\mathrm{O}$ & Amide I & Amide II \\
\hline PBLAsp $(\beta)$ & 1725 & 1634 & 1530 \\
Bu-1 & 1723 & 1634 & 1532 \\
Bu-2 & 1724 & 1634 & 1529 \\
Bu-3 & 1728 & 1634 & 1530 \\
Bu-4 & 1728 & 1634 & 1530 \\
Bu-5 & 1724 & 1634 & 1530 \\
Bu-6 & 1726 & 1634 & 1530 \\
\hline
\end{tabular}

$\mathrm{Bu}-3$ - 6 were lower in wave number than $\mathrm{Bu}-1,2$ and that the as-cast films of $\mathrm{Bu}-1,2$ as well as those of PBLAsp consisted of left handed $\alpha$ helices and that those of Bu-3 -6 consisted of right handed $\alpha$ helices. With an increase in the degree of butylation, left handed $\alpha$ helices transformed into right handed $\alpha$ helices.

By annealing at $140^{\circ} \mathrm{C}$, both left handed and right handed $\alpha$ helices of the as-cast films (Bu-1-6) transformed into $\omega$ helices. Since the steric conditions of the main chain and side chain of copoly(BuLAsp-BeLAsp) are unfavorable to the formation of the $\omega$ helix with the right handed screw sense, ${ }^{16}$ the $\omega$ helix obtained here is considered to be of the left handed helix sense, as in the case of PBLAsp's helix. That is, in Bu-3-6, the $\alpha-\omega$ transition may simultaneously be accompanied with the change from a right handed to left handed helix, in contrast to the $\alpha-\omega$ transition of $\mathrm{Bu}-1,2$ and PBLAsp. The $\omega-\beta$ transformation, ( $\omega$ helix to $\beta$ form) by heating to $210^{\circ} \mathrm{C}$, occurred in all samples (Bu-1-6), as shown in Table V (specially Amide I band).

\section{$X$-Ray Diffraction Analysis}

The spacings calculated from $\mathrm{X}$-ray diffraction photographs for the as-cast films of all copolyaspartates $(\mathrm{Bu}-1-6)$ are given in Table VI. Comparing the $\mathrm{X}$-ray diffraction photographs of the as-cast films of copoly(BuLAsp-BeLAsp) with that of PBLAsp, ${ }^{4}$ the as-cast films were found to consist of $\alpha$ helical chains of low degree of crystallinity. The spacings of the as-cast films of copoly(BuLAsp-BeLAsp) tend to become shorter as the degree of butylation increases, since the length

Table VI. Spacings $(\AA)$ observed in X-ray diffraction photographs of PBLAsp and copoly(BuLAsp-BeLAsp)

\begin{tabular}{cccc}
\hline & $\begin{array}{c}\text { As-cast } \\
\text { films }\end{array}$ & $\begin{array}{c}\text { Films } \\
\text { annealed } \\
\text { at } 140^{\circ} \mathrm{C}\end{array}$ & $\begin{array}{c}\text { Films } \\
\text { annealed } \\
\text { at } 210^{\circ} \mathrm{C}\end{array}$ \\
\hline PBLAsp & 13.2 & 13.9 & 17.1 \\
Bu-1 & 13.2 & 13.9 & 16.7 \\
Bu-2 & 13.2 & 14.0 & 17.0 \\
Bu-3 & 13.1 & 14.0 & 16.6 \\
Bu-4 & 13.0 & 13.8 & 16.7 \\
Bu-5 & 12.8 & 13.8 & 16.8 \\
Bu-6 & 12.7 & 13.8 & 16.6 \\
\hline
\end{tabular}


Table VII. Spacings $(\AA)$ observed in X-ray diffraction photograph of Bu-4

\begin{tabular}{|c|c|c|c|c|c|c|c|}
\hline \multicolumn{2}{|c|}{ As-cast film } & \multicolumn{4}{|c|}{ Films annealed at $140^{\circ} \mathrm{C}$} & \multicolumn{2}{|c|}{ Films annealed at $210^{\circ} \mathrm{C}$} \\
\hline$d_{\mathrm{obsd}}$ & Int. & $d_{\text {obsd }}$ & Int. & $d_{\text {calcd }}{ }^{\mathrm{a}}$ & $h k l$ & $d_{\text {obsd }}$ & Int. \\
\hline & & & & & & 16.66 & vs \\
\hline \multirow{12}{*}{13.00} & vvs & 13.79 & vvs & 13.80 & 100 & & \\
\hline & & 6.85 & w & 6.90 & 200 & & \\
\hline & & 6.15 & $\mathrm{w}$ & 6.18 & 210 & & \\
\hline & & 5.30 & $\mathrm{~s}$ & & & & \\
\hline & & 4.95 & vs & 4.88 & 220 & & \\
\hline & & 4.62 & $\mathrm{~s}$ & 4.60 & 300 & 4.69 & s \\
\hline & & 4.31 & s & 4.36 & 310 & & \\
\hline & & 4.19 & s & 4.26 & 201 & & \\
\hline & & 3.99 & $\mathrm{~s}$ & 4.07 & 211 & & \\
\hline & & 3.42 & $\mathrm{w}$ & 3.45 & 400 & & \\
\hline & & 3.34 & $\mathrm{w}$ & 3.35 & 410 & & \\
\hline & & 3.06 & $\mathrm{w}$ & 3.09 & 420 & & \\
\hline
\end{tabular}

a $d_{\text {calcd }}$ is based on the tetragonal unit cell with $a=b=13.80 \AA$ and $c=5.42 \AA$.

of the $n$-butyl group is somewhat shorter than that of the benzyl group.

The spacings of the films $(\mathrm{Bu}-4)$ annealed at $140^{\circ} \mathrm{C}$ were the same as those of the $\omega$ helix of PBLAsp reported by Green et al. ${ }^{4}$ The $\alpha-\omega$ transition of copoly(BuLAsp-BeLAsp) was also accompanied by a transformation from hexagonal to tetragonal packing. Although the spacings of the ascast films ( $\alpha$ helix) become shorter as the degree of butylation increases, the spacings of the films annealed at $140^{\circ} \mathrm{C}(\omega$ helix) were approximately the same for all copolyaspartates, as shown in Table VI. These facts suggest that stacks between the benzyl and butyl groups can be formed in the $\omega$ helix and that conformation of a side chain in the butyl-Laspartate takes on a somewhat extended form. This explanation may probably be extended to the cocrystallization or isomorphous replacement observed in copolyamide. Edgar and $\mathrm{Hill}^{17}$ noted, from calculations based on normal bond lengths and angles, that the distance between the carboxyl groups in terephthalic and adipic acid is almost the same. This was observed for the crystalline part of copoly(hexamethylene adipamideterephthalamide). Thus, it is reasonable to suggest that stacks between the benzyl and butyl groups take place in the $\omega$ helix.

The films annealed at $210^{\circ} \mathrm{C}$ transformed into the $\beta$ form with spacings of $16.6-17.1 \AA$ and $4.6-$ $4.7 \AA$, as shown in Tables VI and VII. The former is considered to correspond to the intersheet spacing of the $\beta$ form and the latter, to the backbone spacing in the sheet.

\section{Dynamic Viscoelastic Behavior}

The dynamic modulus $E^{\prime}$ and $\tan \delta$ at $110 \mathrm{~Hz}$ are shown as functions of temperature in Figure 1. Viscoelastic behavior may be classified into two patterns, one for $\mathrm{Bu}-1,2$ and the other for $\mathrm{Bu}-3-6$. These two patterns correspond to the different respective transformations from a left handed $\alpha$ helix to a left handed $\omega$ helix in $\mathrm{Bu}-1,2$ and from a right handed $\alpha$ helix to a left handed $\omega$ helix in $\mathrm{Bu}-$ $3-6$ as described in the section of IR absorption spectroscopy and X-ray diffraction analyses.

The dynamic modulus of $\mathrm{Bu}-1,2$ in room temperature region was lowered to some extent by butylation and increased to the modulus value of the $\omega$ helix of PBLAsp above $c a \cdot 100^{\circ} \mathrm{C}$, the $\alpha-\omega$ transition temperature. A steep decrease based on the transformation to the $\beta$ form was observed near $200^{\circ} \mathrm{C}$. The $\tan \delta$ dispersion near $60^{\circ} \mathrm{C}$ is considered to result from side chain motion. ${ }^{18}$

For $\mathrm{Bu}-3-6$, remarkable changes in $E^{\prime}$ and tan $\delta$, corresponding the $\alpha-\omega$ transition accompanied by a reversal from a right handed $\alpha$ helix to left handed $\omega$ helix, were observed near $130^{\circ} \mathrm{C}$. The change in $E^{\prime}$ was probably due to opening of hydrogen bonds and then refolding to the opposite helix accompanied by the formation of the $\omega$ helix. 


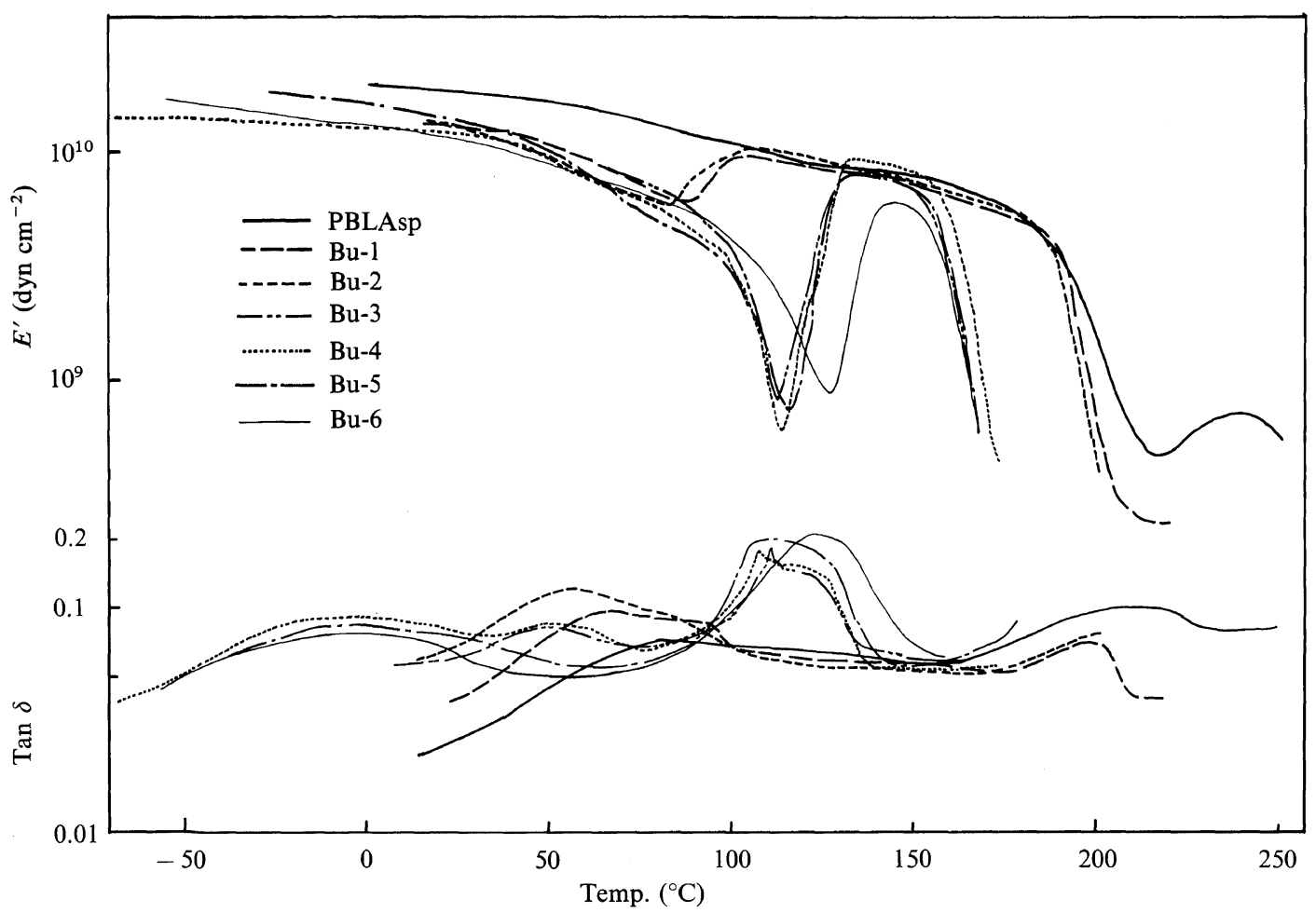

Figure 1. Dynamic modulus $E^{\prime}$ and $\tan \delta$ at $110 \mathrm{~Hz}$ as functions of temperature for PBLAsp and Bu-1-

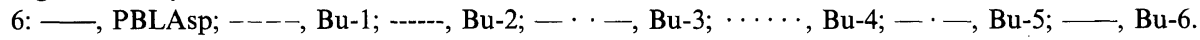

Figure 2 shows a dynamic modulus and $\tan \delta$ for $\mathrm{Bu}-2,5$ of the as-cast films and films annealed at $140^{\circ} \mathrm{C}$ and $210^{\circ} \mathrm{C}$. By annealing at $140^{\circ} \mathrm{C}$, the $\omega$ helix was formed and no dispersion was observed up to $140^{\circ} \mathrm{C}$ in either $\mathrm{Bu}-2$ or $\mathrm{Bu}-5$. It was thus confirmed that the $\alpha-\omega$ transition is irreversible and that the change in $E^{\prime}$ near $100^{\circ} \mathrm{C}$ with the $\tan \delta$ dispersion near $60^{\circ} \mathrm{C}$ for $\mathrm{Bu}-2$, and the change in $E^{\prime}$ near $130^{\circ} \mathrm{C}$ for $\mathrm{Bu}-5$ observed for the as-cast films are due to the $\alpha-\omega$ transition with the same helix sense and a reversal in helix sense, respectively. The $\beta$ form was prepared by annealing at $210^{\circ} \mathrm{C}$. The dynamic modulus of the $\beta$ form is much smaller than those of the $\alpha$ and $\omega$ helices. Both Bu-2 and Bu5 show the $\tan \delta$ dispersion near $120^{\circ} \mathrm{C}$, corresponding possibly to the side chain motion of the $\beta$ form. The $\omega-\beta$ transformation was also found to be irreversible by an annealing experiment.

\section{Thermal Analysis}

The DTA thermograms of all copoly(BuLAsp-
BeLAsp) are shown in Figure 3. The exothermic peak (the $\alpha-\omega$ transition) and the endothermic peak (the $\omega-\beta$ transformation) appeared for all samples. The number in the thermogram is the transition temperature. The thermograms were also classified into the two patterns described above, one for $\mathrm{Bu}-1$, 2 and the other for Bu-3-6.

The exothermic peak of $\mathrm{Bu}-1,2$ shifts from the transition temperature of PBLAsp, $127.3^{\circ} \mathrm{C}$ to $c a$. $100^{\circ} \mathrm{C}$ with a small degree of butylation. These thermal results correspond to the viscoelastic behavior of Bu-1, 2.

The exothermic peak of $\mathrm{Bu}-3-6$ appeared at nearly the same temperature as that of PBLAsp and became considerably sharper and larger compared with the peak of PBLAsp given in Table VIII. This fact along with the IR absorption spectroscopy and $\mathrm{X}$-ray diffraction analysis may be an adequate basis for concluding that this large sharp peak is ascribable to the transition from a right handed $\alpha$ helix to a left handed $\omega$ helix. Kyotani and Kanetsuna have 


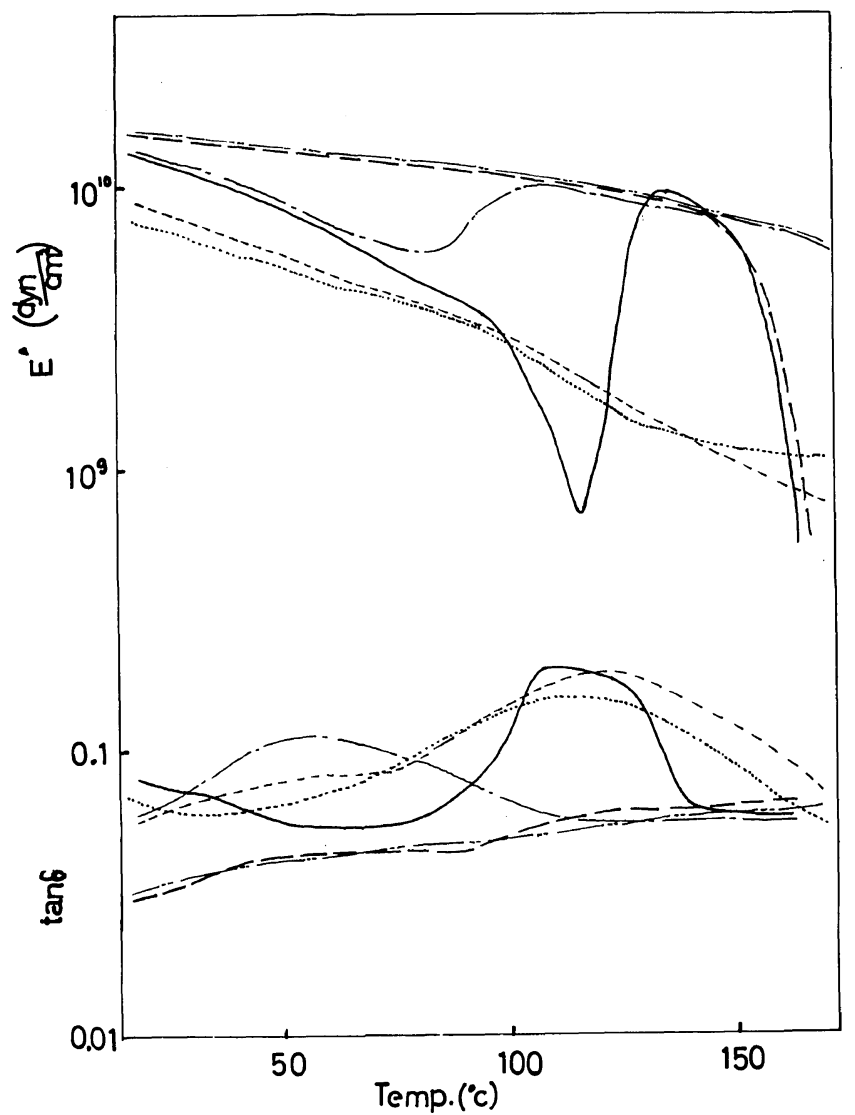

Figure 2. Dynamic modulus $E^{\prime}$ and $\tan \delta$ at $110 \mathrm{~Hz}$ as functions of temperature for $\mathrm{Bu}-2$ and $\mathrm{Bu}-5$. As cast film: - - - Bu- 2 ; — - Bu-5. $140^{\circ} \mathrm{C}$ annealing:.,-- Bu-2;,$---- \mathrm{Bu}-5 ; 210^{\circ} \mathrm{C}$ annealing: -----, Bu-2; $\cdots$, , Bu-5.

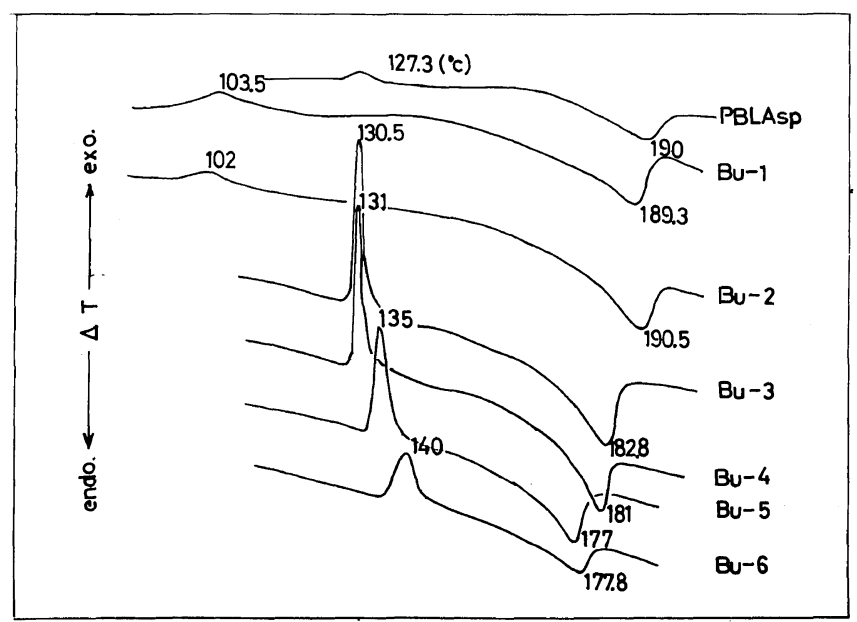

Figure 3. DTA thermograms for PBLAsp and Bu-1-6. The numbers in the figure are the transition temperatures. 
The Structure and Properties of Copolyaspartate I.

Table VIII. The $\alpha-\omega$ transition enthalpy

\begin{tabular}{cc}
\hline & $\Delta H / \mathrm{kcal} \mathrm{mol}^{-1}$ \\
\hline PBLAsp & 0.18 \\
Bu-1 & 0.28 \\
Bu-2 & 0.32 \\
Bu-3 & 1.46 \\
Bu-4 & 1.44 \\
Bu-5 & 1.28 \\
Bu-6 & 0.90
\end{tabular}

studied the relation of the $\alpha-\omega-\beta$ transition with molecular weight ${ }^{6}$ and found that cast films with a molecular weight of $25 \times 10^{4}$ show the left handed $\alpha$ helix -left handed $\omega$ helix- $\beta$ form transition and cast films with a molecular weight of 3,300 show the right handed $\alpha$ helix-left handed $\omega$ helix- $\beta$ form transition. The $\alpha-\omega$ transition of low molecular weight cast film involves a reversal of the helix sense and exhibits an exothermic peak larger than that of high molecular weight cast film. Our results agree well with those of these authors in regard to helix sense. It is reasonable to suggest that in $\mathrm{Bu}-3-6$, the reversal from a right handed to a left handed helix causes the exothermic peak to be sharp and large. Therefore, the following three mechanisms may possibly occur simultaneously near $130^{\circ} \mathrm{C}$ for $\mathrm{Bu}-$ 3-6: the $\alpha$ helix to $\omega$ helix transition, the chain packing transformation from hexagonal to tetragonal packing, and the reversal from a right handed to a left handed helix. The enthalpy of the $\alpha-\omega$ transition obtained by the DSC (Table VIII) becomes smaller with increasing butylation degree for Bu-3-6. This fact suggests that the stacking energy between butyl groups is smaller than that between benzyl groups.

The endothermic peak accompanied by a $\omega-\beta$ transformation, appeared for all copoly(BuLAspBeLAsp). The $\omega-\beta$ transformation may be classified into two patterns, one for $\mathrm{Bu}-1,2$ and the other for
Bu-3-6. The former transformation temperature is about 10 degree higher than the latter. Similarly, two types of dynamic viscoelastic behavior may be designated, although the transformation temperatures are different. These results suggest that the $\omega$ helix which does not undergo a reversal in helix sense is much more stable than that which does so.

\section{REFERENCES}

1. E. M. Bradbury, A. R. Downie, A. Elliott, and W. E. Hanby, Proc. R. Soc., London, Ser. A, 259, 110 (1960).

2. E. M. Bradbury, L. Brown, A. R. Downie, A. Elliott, R. D. B. Fraser, and W. E. Hanby, J. Mol. Biol., 5, 230 (1962).

3. L. Bragg, J. C. Kendrew, and M. F. Perutz, Proc. $R$. Soc., London, Ser. A, 203, 321 (1950).

4. D. B. Green, F. Happey, and B. M. Watson, Eur. Polym. J., 6, 7 (1970).

5. H. Obata and H. Kanetsuna, J. Polym. Sci., A2, 9, 1977 (1971).

6. H. Kyotani and H. Kanetsuna, J. Polym. Sci., 10, 1931 (1972).

7. M. Fukagawa, Y. Tsujita, and I. Uematsu, unpublished data.

8. B. R. Malcolm, Nature, 219, 929 (1968).

9. B. R. Malcolm, Biopolymers, 9, 911 (1970).

10. Y. Takeda, Y. Iitaka, and M. Tsuboi, J. Mol. Biol., 51, 101 (1970).

11. E. M. Bradbury, B. G. Carpenter, and R. M. Stephens, Biopolymers, 6, 905 (1968).

12. E. M. Bradbury, B. G. Carpenter, and R. M. Stephens, Macromolecules, 5, 8 (1972).

13. H. Leuchs, Ber., 39, 857 (1906).

14. P. Doty, S. H. Bradbury, and A. M. Hiltzer, J. Am. Chem. Soc., 78, 947 (1956).

15. E. M. Bradbury, B. G. Carpenter, and H. Goldman, Biopolymers, 6, 837 (1968).

16. R. F. McGuire, G. Vanderkooi, F. A. Momany, R. T. Ingwall, G. M. Crippen, N. Lotan, R. W. Tuttle, K. L. Kashuba, and H. A. Scheraga, Macromolecules, 4, 112 (1971).

17. O. B. Eagar and R. E. Hill, J. Polym. Sci., 8, 1 (1952)

18. Y. Tsujita and I. Uematsu, Polym. J., 6, 274 (1974). 